\title{
Chapter 12 \\ Constructing (Inter)Disciplinary Identities: Biographical Narrative and the Reproduction of Academic Selves and Communities
}

\author{
Carlos Cuevas-Garcia
}

\subsection{Introduction}

Interdisciplinarity has become so prominent in academia and science policy that scholars have started paying attention to its implications for the development of academic careers and individual and collective identities (OECD 1972; RCUK 2015; European Commission 2011; National Academy of Sciences 2005; Holley 2015; Calvert 2011; Bartlett et al. 2016; Leahey et al. 2017; Klein and Falk-Krzesinski 2017). There are studies that point to a number of concerning findings-for example, that interdisciplinary work is perceived as work of low quality; that it involves personal, emotional, and intellectual challenges because interdisciplinary researchers may not be perceived as experts, and because they may not fulfil the expectations of their disciplinary peers (Buanes and Jentoft 2009; Pfirman and Martin 2010). Interdisciplinarity has also been described as a professional challenge because it does not offer a 'clear career track from an undergraduate major to professorial appointment' as traditional disciplines do (Turner 2000, p. 60; Abbott 2001). Although interdisciplinarity has gained popularity, Henkel (2005) argues that having a disciplinary identity has remained relevant because in a competitive environment such as academia, having a track record in a single discipline increases individuals' chances of attracting funding, accumulating rewards, and obtaining a permanent position. Despite the existence of inter- or trans- disciplinary doctoral programmes, Felt et al. (2013) argue that these are 'not necessarily perceived as being particularly supportive when aiming for an academic career' (p. 520). In their introduction to this volume, Kastenhofer and Molyneux-Hodgson summarise

\footnotetext{
C. Cuevas-Garcia $(\bowtie)$

Munich Center for Technology and Society, Technical University of Munich, Munich,

Germany

e-mail: carlos.cuevas@tum.de
} 
coherently these concerns observing that 'attachments to older labels remain strong even when a scientist ventures into new waters (Molyneux-Hodgson and Meyer 2009), often due to concerns about the transitory nature of funding and research policies' (p. 4).

Other studies, however, provide a more nuanced picture. There are studies that identify variations in how interdisciplinary research is perceived by different disciplinary communities (Calvert 2011; Klein 2010; Huutoniemi et al. 2010; Barry et al. 2008). In a survey that asked 600 social scientists from different disciplines to agree or disagree with the statement 'In general, interdisciplinary knowledge is better than knowledge obtained by a single discipline', 57.3\% of economists disagreed or strongly disagreed with the statement, compared to $25.3 \%$ of sociologists and 9.4\% of psychologists (Gross and Solon 2007). In addition to these variations, Garforth and Kerr (2011) note that interdisciplinarity is regarded differently in different institutional contexts; for example, in traditional university departments and in applied contract research units. Accordingly, scholars can accumulate different forms of scientific, academic, and symbolic capital (Bourdieu 1988) depending on the type of work (disciplinary or interdisciplinary) that they do and the type of institution in which they work. Based on these observations, they suggest that discussions about the personal and professional implications of interdisciplinarity should pay more attention to institutional contexts and to individual academic trajectories.

This complex scenario makes it challenging to understand the meaning of increasing calls for interdisciplinarity for the articulation of individual and collective academic identities. How do scholars involved in interdisciplinary research conceive of their place within academia and how do they negotiate their academic identities? Do they focus on developing and performing clearly distinguished disciplinary identities, or rather on negotiating an identity combining elements from different disciplines? Besides disciplinary labels, what other details are relevant in the construction of an academic identity? And how do negotiations of identity differ across disciplinary communities? The literature provides initial insights for addressing these questions, but the complexity of the topic calls for more refined studies and methodological approaches. Intending to contribute to addressing these questions, this chapter examines how scholars involved in interdisciplinary research construct and negotiate their academic identities through biographical narratives, paying particular attention to how the local contexts of the individuals' main disciplines shape their identity constructions.

Academics' biographical narratives are an interesting but underexplored type of data. They provide access to individuals' unique trajectories, but they are more than neutral descriptions of life events. Through biographical narrative, individuals can negotiate their identities as specific types of people and as members of particular communities, they can attribute desirable personal characteristics to themselves and to others, and they can justify past and future actions and decisions. Furthermore, as it will be argued in this chapter, academics' biographical narratives might contribute to the establishment, maintenance, and reproduction of academic disciplines. The chapter will focus on the accounts provided by individuals from four different 
disciplines, some of which are characterised by their interdisciplinary nature and others by their insularity, including mathematics, economics, computer science, and archaeology. These data belong to a broader sample of 27 interviews with researchers and administrators of all ranks and faculties from a large, researchoriented British university, which were collected between December 2012 and September 2013 for a project that looked at the discursive construction of the interdisciplinary self.

The analysis presented in this chapter draws on Taylor and Littleton's (2006, 2008 , 2012) narrative-discursive analytical approach, a novel approach that 'offers a way of investigating the social nature of biographical talk' (2006, p. 23). According to Taylor and Littleton (2006), biography is 'a situated construction' in which the 'wider discursive environment is implicated' (p. 23). Rooted in Foucauldian theory and ethnomethodology, the theoretical assumption is that meanings of objects and subjects are constructed through talk and social interaction. It follows from this assumption that individuals are, to some extent, active in claiming, constructing, and negotiating their identities. They are not entirely free because they are constrained by their unique life trajectories and by meanings that are socially and historically available within the communities they inhabit, such as values attached to specific categories and to the ways in which lives are expected to develop (Taylor 2007). For example, how individuals are meant to become members of a disciplinary community, and how interdisciplinarity is valued within specific academic contexts. This approach provides a number of analytical concepts (namely canonical narrative, breach, identity trouble, and repair) that facilitate investigating how academics construct their identities within the interactional context of an interview while dealing with these widely established meanings.

The intention here is not to suggest that biographical narrative is the only or the most important resource for the construction of an academic identity. Scholars' engagement with particular communities, their research outputs, their grant submissions, and their engagement with other nonhumans (i.e. laboratories and research settings, materials, and instrumentation) are also relevant (Michael 1996). Yet, by suggesting an in-depth study of biographical narrative, the intention is to contribute to the accumulation of diverse and detailed methodologies for the study of academic identities. Biographical narratives are interesting because of their relative flexibility, variability, and adaptability to the interactional and the institutional context in which they are produced. In the next sections, the chapter will examine the interrelated histories of the concepts 'identity' and 'discipline' (12.2). It will describe the methodological approach, the analytical categories, and the data in more detail (12.3), and then the analysis will be presented (12.4). The chapter will conclude by suggesting that individuals' biographical narratives are valuable research objects that deserve detailed analytical attention since they may contribute to rendering the narratives that constitute the 'core' of a scientific discipline, little by little, more heterogeneous (12.5). 


\subsection{How Disciplines and Identity Interrelate}

The study of disciplinary and interdisciplinary identities requires a reflexive and cautious approach because the notions of 'academic discipline' and 'identity' interrelate in two distinct and peculiar ways (Gleason 1983; Wetherell 2010; Forman 2012; Sugimoto and Weingart 2015). The first one has to do with the fact that constructing disciplinary boundaries and creating identities are closely related activities; the second one is concerned with how uses of the term 'identity' reinforce disciplinary boundaries. This section begins with the first form of interrelation. Reviewing accounts about the origin of disciplines should contribute to understanding not only how these acquired their current appearance and their outwardly independent identities but also the relevance of narrative for the achievement of these endeavours.

Debates about how knowledge should be produced, documented, and transmitted, whether by a specialised or by a holistic approach, have existed since the eighteenth and nineteenth centuries (Klein 1990). According to Forman (2012), in the nineteenth century the notion of disciplinarity was only an ideal, but by the middle decades of the twentieth century the ideal became taken for granted, as if it had eventually been achieved. Forman contends that historians of science contributed extensively to establishing the idea of disciplinarity as a given, and that the compilation of disciplinary histories during the eighteenth and nineteenth centuries was motivated 'in part by the aim of creating clear and distinct disciplinary identities' (2012, p. 62). He argues that in writing the history of individual disciplines, historians of science took for granted the postulate of social or institutional differentiation, a postulate that explains that societies follow 'a natural and inevitable process of increasing functional differentiation of social, cultural, and occupational roles, resulting in increasingly autonomous institutions operating to ever-higher functional standards' (Forman 2012, p. 69). Scientific disciplines represented the highest level of institutional differentiation, and it is likely that historians produced disciplinary histories that intended to validate this postulate.

In a similar way, Schaffer (2013) argues that disciplines seem to be different and independent from each other because they tell stories about where they come from, where they are, and where they are going. To Schaffer, these stories are performative in the sense that they 'provide a rationale and means for the pursuit of the disciplinary enterprise' (2013, p. 57), and they make disciplines look like 'well-institutionalized homogeneous systems of formal behaviour' (p. 58). However, sceptical of these stories, he argues that all disciplines are hybrid and internally fragmented, and that all stories of disciplinary unity are, in fact, misleading. In a more recent study, Sugimoto and Weingart (2015) suggest that different disciplinary histories provide different and even contradictory criteria of what counts as a discipline, and that these texts, in telling the history of a discipline, establish the criteria of disciplinarisation.

These studies suggest that the boundaries that demarcate one discipline from another, and thus where disciplinarity ends and interdisciplinarity begins, are not as clearly defined as it might be assumed. From this assumption it follows that 
disciplinary and interdisciplinary identities can be permanently open to negotiation. Yet, this is not to deny that disciplinary boundaries are real in their consequences: they define how funding is distributed, who has authority over specific problems, and, many times, who gets hired and who doesn't (Henkel 2005).

The second way in which disciplines and identity interrelate stems from the fact that different uses and understandings of the term 'identity' allow for the construction and maintenance of disciplinary boundaries. According to Gleason (1983), since the term 'identity' became popular in academia during the 1950s and 1960s, it quickly started to be used in two forms: one that referred to it as a personal and subjective achievement, and other that referred to it as a social category. Since then, the study of identity has been marked by a bifurcation that distinguishes personal identity from social identity, as if the distinction between the internal, personal and psychological, and the external and social were clearly demarcated. However, as Wetherell (2010) argues, such binaries are to some extent a product of 'priority disputes between sociology and psychology and [of] accusations of blindness on both sides' (p. 10). She explains that research on identity has both built on and criticised the division between the personal and the social sides of identity. Moreover, she asserts that the debate will not cease any time soon because it is not possible to investigate any aspect of identity without being struck by the extent to which the social is personally owned, and by the myriad ways in which people make social locations psychological' (Wetherell 2010, p. 12).

Studies of disciplinary and interdisciplinary people and identities tend to overlook that the division between the personal and the social dimensions of identity is to some extent a product of disciplinary disputes, and they tend to focus on either one side or the other. Amongst the studies that look at the social side of academic identity, one feature that has been explored is the use of disciplinary labels. Pinch (1990) argues that scientists use disciplinary labels in flexible ways, shifting from one to another in order to claim certainty over specific problems and uncertainty over others. Brew (2007) illustrates this flexibility in great detail. In a study that included interviews with 71 researchers from several fields in the UK and Australia, less than one third identified themselves with single disciplinary labels. By contrast, most of the interviewees provided tentative 'nested' or 'confluent' identities between or across different disciplines and specialist areas, using clauses such as 'I suppose', 'I think you could say', 'I guess', and 'it could also be'. She concludes that studies of disciplinary and interdisciplinary identity should take into account more fluid metaphors that could 'capture the ... rhetorical and reflexive nature of academics' disciplinary affiliations' (Brew 2007, p. 423). Moreover, she suggests that interdisciplinarity should be seen as a common practice of academics rather than a deviant one.

Pinch's and Brew's studies challenge the view that disciplines are fixed entities, and they point to the flexible and rhetorical character of disciplinary identities. With that, they avoid taking the dividing line between disciplinary and interdisciplinary identity for granted, just as the historical studies described earlier suggest. However, that flexibility and the search for more fluid metaphors say little about the individuals' unique trajectories and about the institutional contexts in which they work. It is 
as if Pinch and Brew looked at the most obviously 'social' side of identity at the expense of the 'personal' and individual side.

Analyses that are limited to features of identity that can be categorised as 'social' overlook other important elements of identity construction that would count as 'personal' or even 'psychological'. By contrast, other studies suggest that interdisciplinary researchers have very peculiar personal characteristics. Klein (1990), for example, suggests that interdisciplinary researchers are divergent thinkers 'who may not be too narrow to deal with cross-cutting issues', who have 'a high degree of ego strength, a tolerance for ambiguity, considerable initiative and assertiveness, a broad education, and a sense of dissatisfaction with monodisciplinary constraints' (p. 183). Similarly, Castán Broto et al. (2009) claim that 'if people combine knowledge and have a certain quality of mind and personality they will enjoy conducting interdisciplinary research despite, and because of, its challenges' (p. 928). What is striking in these studies is that, paradoxically, by describing these personal characteristics, they contribute to the construction of the 'interdisciplinary researcher' as a distinct social category.

The arguments above underline that the study of how academic, disciplinary, and interdisciplinary identities are constructed should not be restricted to analyses of the use of disciplinary labels alone. Moreover, they suggest that the study of interdisciplinary identities has to be critical of fixed categories such as 'disciplinary', as opposed to 'interdisciplinary', and 'personal', as opposed to 'social'. For instance, scholars who identify themselves as critical social psychologists, such as Gergen (1973) and Billig (1991, 2008), argue that the boundary between the study of psychology and the study of history is blurry, and they suggest that the content of our thoughts has a social history and depends on the ideologies of our time. Applying this same argument to the content of psychology itself, they contend that the way we understand and talk about psychological phenomena (attitudes, identity, rationality, remembering, forgetting, etc.) is historically contingent. Thus, whatever we understand now as social and as psychological should not be so easily taken for granted.

Gergen and Billig's thinking has been influential in the development of discursive psychology (Potter and Wetherell 1987; Wetherell 2008; Billig 2012), the field that provides the background for the analysis presented in this chapter. The purpose of this field is to explore the ways in which individuals use psychological language and categories in conversation and social interaction to construct particular versions of the self and the world. The purpose is not to reduce psychological phenomena to social phenomena, but to illustrate how effective and flexible psychological language is in the production of justifications and accountability. 


\subsection{Methodology}

\subsubsection{Analytical Approach and Analytical Categories}

The analysis of the data presented in this chapter draws on the 'synthetic narrativediscursive approach' that Taylor and Littleton (2006, 2008, 2012) developed in a long-term study of creative identities. They call it a synthetic approach because it pays attention both to how subjects are positioned by wider discourses as well as to how they can challenge and re-negotiate the meaning of those positions.

The analytical categories used in this approach are canonical narrative, breach, trouble, and repair. The notion of the canonical narrative (Bruner 1990) refers to the ways in which lives are expected to unfold or to the 'expected connections of sequence and consequence which create narrative structure and trajectories' (Taylor and Littleton 2006, p. 26). A canonical narrative 'can provide a logic for talking about personal circumstances, life stories and decisions' (Taylor 2007, p. 6). The relevance of this category does not rely on its accuracy but on its strength as a discursive resource.

A rupture from the canonical narrative is called breach, and, as Taylor and Littleton (2006) suggest, 'unexpected associations' or connections become a source of trouble which requires repair (p. 27). The notion of identity trouble refers to identities that are inconsistent with conventional expectations and also to those that are difficult to adopt because they are inconvenient, undesirable, or incompatible with other identities that speakers may have previously adopted. In most occasions, breaching from the canonical narrative leads to trouble, and in those circumstances repair is expected.

\subsubsection{Empirical Material}

The empirical material examined in this chapter was collected as part of a $\mathrm{PhD}$ project focused on the discursive construction of the interdisciplinary self. The purpose was to identify how interdisciplinary researchers construct narratives of who they are and how they became interdisciplinary, also asking questions such as what are their professional challenges and expectations, how are they perceived and described by others, and what is expected of them. Semi-structured interviews were conducted with 14 male and 13 female researchers and administrators whose research descriptions suggested their involvement in interdisciplinary work. Potential interviewees were selected after searching the university website, and others were recommended by the interviewees. The interviews lasted between 40 and 70 minutes, and all of them were fully recorded and transcribed. The research obtained ethical approval from the Department of Sociology of the same university. 
In order to secure anonymity, all names of individuals were changed to pseudonyms, and some details of the fields in which or with which they work were also changed.

The analysis will focus particularly on the narrative constructions of interviewees working on mathematics, computer science/bioinformatics, economics, and archaeology. These interview extracts were selected because they illustrate some of the different possibilities in which identities can be negotiated across disciplines. The four interviews used in this chapter are representative of the whole sample in the sense that they demonstrate patterns of how the interviewees drew on personal details of their lives, on conventional narratives and wider social meanings, and on articulations of repair provided whenever they distanced from the conventional narratives. These four interviewees worked in traditional disciplinary departments at the moment of the interview.

In order to inform the analysis, it is valuable to provide some information about the particular fields of the interviewees examined in this chapter. To begin with, mathematics and mathematicians' identity have a distinct place in discussions of interdisciplinarity and of academic identity because, on the one hand, 'mathematics enables work in many different disciplines, from the natural and physical sciences to the social sciences and fine arts', and because it 'can also support knowledge integration across disciplines' (Fisher and Beltran-del-Rio 2010, p. 88). However, despite the contact of mathematics with other disciplines, the identity of the mathematician is a particularly strong one. For instance, mathematicians, and possibly physicists - who draw strongly on mathematics-have received more attention than other scholars in popular culture (Haynes 2016), where they are often portrayed as clever individuals with a great passion for knowledge, and at times embodying the prototype of the lone genius (Mialet 1999). One can think of Albert Einstein, Richard Feynman, John Nash, and Stephen Hawking. Other disciplines lack this sort of well-known personalities.

Bioinformatics, which draws on biology, computer science, and mathematics, is a clear example. The issue of bioinformatics is that it 'is often seen as being neither good biology, nor good computer science, but, rather, as a service provider to biology' (Bartlett et al. 2016, p. 188). With such a connotation, it is interesting to examine how researchers involved in bioinformatics negotiate their identities.

The negotiation of disciplinary and interdisciplinary identities in economics is also an interesting subject. Fourcade et al. (2015) note that economists have a high regard for scientific purity and that they rely strongly on the use of formal methods. Moreover, economics has strong connections to wealth and power, and these conditions provide the discipline with a sense of superiority. A consequence is that economics is more insular than other disciplines, and there is distrust on the interpretivist methods of other social sciences. According to one of Fourcade's (2009) interviewees, economists condemn highly those who do not follow the epistemological preferences of the discipline and who may present data that sounds 'anecdotal'. In this context, engaging with other disciplines might be risky.

At the opposite extreme, archaeology is a discipline that draws on a huge variety of methods and theories from other disciplines, such as the natural sciences, the arts, and the humanities. Kristiansen (2009) argues that the discipline's ambitious aim of 
studying and preserving the past would not be possible without the contributions of zoology, environmental sciences, physics, medicine, history, and anthropology, amongst other disciplines. Furthermore, he notes that studies that are perceived as the first modern archaeological studies 'were based upon interdisciplinary work, which was to remain a dominant feature in archaeological practice until this day' (p. 28).

\title{
12.4 Analysis
}

The analysis presented below focuses mainly on the interviewees' responses to the first question I asked, 'can you please tell me about your background?' The first extract comes from Lawrence, a professor of applied mathematics who spent most of his career in a publicly funded laboratory before moving to academia. Curiously, he never did a $\mathrm{PhD}$, and his first academic post was a professorship. In the years he has worked at the university he has collaborated with people in engineering, and he often participates in interdisciplinary workshops.

\subsubsection{Lawrence - Mathematics}

\begin{abstract}
I think it was always my ambition to become a scientist of some kind or another. From as long ago as I can really remember-probably goes back to primary school. But then there was a period when I went to a grammar school and I guess some of the way science was taught didn't captivate me, and the mathematics I was taught wasn't that exciting. And in fact I come from a farming background; I decided after I've done my $\mathrm{O}$ levels that I was gonna basically go and work at my father's farm because that was kind of work he'd done and his father before him. But he did me the biggest favour he could, he gave me all the dirty nasty jobs, and I decided there must be an easier way making a living than this. And I went back and I started doing A levels and I did very traditional hard science-A levels, maths, further maths, physics and chemistry. And I've been an average student, or probably better than average student, I would say. But, I found when I started doing A level and further maths I really enjoyed it, and I was pretty good at it, actually. And I enjoyed the physics; chemistry not so much, but I basically decided that I really wanted to go to university and do science. So I went to Cambridge and I did mathematics there. I got a first [class degree] and I was pretty good. I was actually, to my surprise, better than most people, not everybody, but most people.
\end{abstract}

In this extract, it is interesting to note that even though the interview was about interdisciplinarity, Lawrence gave priority to presenting himself as a gifted mathematician. Secondly, one can note that the extract contains references of personal traits, social categories, and even a description of Lawrence's family environment. In that way, one can see that even though the narrative is uniquely personal, it is also shaped by widely established social meanings. To some extent, the details of the family environment can be interpreted as a confirmation of the skills that Lawrence attributes to his young self. 
As mentioned earlier, mathematicians are often portrayed as clever individuals and as the prototype of the lone genius. In line with this image, Lawrence describes his early ambition, passion, and proficiency in science and mathematics. One crucial part in the story is that he refers to a time when he lost his usual motivation and thought he would work on a farm just as his ancestors did. Yet, Lawrence narrates that his father gave him only dirty and nasty work, which to him was like a favour because this encouraged him to reconsider his plans for the future, to take his fate back into his own hands, so to speak, and return to the academic track. The story can be read as if Lawrence's father knew he had a gifted son whose place was in academia, not on a farm, and this story seems to corroborate that Lawrence did indeed have the skills he claims to have. Since the different elements included in the narrative are well integrated with each other, it is hard to challenge the identity that Lawrence articulated during the interview, and thus he is out of 'identity trouble', and 'repair' is not required. The case is different for the following interviewee, a computer scientist working in bioinformatics.

First, however, it is relevant to mention identity troubles that two other computer scientists referred to during the interviews. Jane, who works in systems and synthetic biology, argued that the 'scientific' status of computer science is often played down by specialists from other disciplines when it is called 'information technology' rather than computer science. Similarly, Robert, who works in computer vision and systems biology, argued that in his interdisciplinary collaborations he has to avoid being taken as somebody's 'IT guy' or 'data monkey' by doing work that is interesting 'from a computer science point of view'. These arguments suggest that for computer scientists involved in interdisciplinary research, it is important to be recognised as scientific specialists rather than as service providers. These arguments also serve as further background to interpret Blanc's biographical narrative.

\title{
12.4.2 Blanc-Computer Science and Bioinformatics
}

\begin{abstract}
My background is computer science; I studied straight computer sciences from my undergraduate up to the $\mathrm{PhD}$, which I did in the area of machine learning. And then I was looking for postdocs in my research area; I found one which was an application of machine learning to bioinformatics here at the university. And that's when I started to open to other, started doing a bit of interdisciplinary research. Was still core computer science but of course we had chemist collaborators, so it was the time I started understanding new languages and seeing different cultures. And now most of the work I do is applied and in collaboration with experimentalists, mostly in biology but across different schools.
\end{abstract}

Blanc describes a sequence of steps through which he has become a disciplinary specialist: he studied computer science from his undergraduate to his doctoral degree, and his postdoctoral career has led him to even more specialised research areas.

In this extract, it is important to pay attention to the rhetorical work that the little words do. First, Blanc describes that he studied 'straight' computer science from the 
undergraduate degree to the $\mathrm{PhD}$. He then emphasises that he was looking for postdocs in 'his' research area and found one which was 'an application' of this area to a particular field. Even when he describes the moment when he 'opened' up to interdisciplinary research, he emphasises that it was only ' $a$ bit' of interdisciplinary research and that it was 'still core computer science'. These little words help Blanc to adopt an identity that is hard to challenge: he is a specialist, not a bioinformatics technician working for the biologists or for any other specialists.

The following interviewee, Lindsay, also accounted carefully for her interdisciplinary engagement. During the interview, she said 'I have been interested in development since I was sixteen, I studied economics because I was interested in development'. She also expressed critical views of interdisciplinarity and of interdisciplinary researchers, who, to her, 'may not be as rigorous as their disciplines may require'.

\subsubsection{Lindsay - Economics}

I'm an economist. I did my PhD at Cambridge. My $\mathrm{PhD}$ thesis was on family business networks in Peru. As a consequence of that research — and I suppose you can say that research was part of a process by which I became interested in kinship. In my early postdoc work I was seeking ideas about methods that could be used to do empirical work for the subject I was interested in and I didn't restrict myself to talk to economists. So basically I became interdisciplinarily interested in that time, I guess.

Similar to the case of Lawrence in a previous extract, Lindsay provides a clear disciplinary identity and the name of the prestigious university where she studied. It is common knowledge that prestigious universities have high admission requirements; therefore this detail reveals that she had a high quality academic performance before enrolling in her PhD programme. With this, she presents herself not as a common economist but as an economist with a very strong academic background and as a disciplined person with a clear ambition. In that way, details from Lindsay's unique trajectory and wider social meanings are combined so that she can portray herself as a hard-working academic specialist. In this extract and in Lindsay's argument that she was interested in development by the time she was sixteen, it is possible to identify a narrative that contains features also found in the accounts that Lawrence and Blanc provided. These include early interests and passion for a specific field, premature skills in this field, clear career goals, and a trajectory within that same field. Taking these features together, this narrative can be suggested as a canonical narrative that allows individuals to portray themselves as single discipline specialists.

In the second half of the extract, Lindsay specifies that her interests on the topic that led her to engage with other disciplines were an outcome of the research she undertook during the $\mathrm{PhD}$. Her use of clauses such as 'as a consequence' and 'part of a process' point to a breach from the canonical narrative, but they also minimise the extent of this breach. Thus, these clauses can be read as rhetorically oriented to 
'repair' the breaches from the canonical narrative and avoid giving the impression that she has driven her career in an undisciplined way or followed academic fashions. Moreover, the clauses suggest that Lindsay's interdisciplinary engagement was the product of a carefully calculated move. Finally, her claim that she 'didn't restrict [herself] to talk to economists' suggests that being closed down to one's own discipline is, in fact, a restriction and not the most desirable way to conduct academic work. In that way, she 'repairs' or justifies her engagement with the 'outside' of the discipline.

The three interview extracts analysed so far have in common that the individuals present themselves with a clear disciplinary identity and as specialists. However, the following extract provides a different picture.

\subsubsection{Julia-Archaeology}

Throughout my school years I was told that I was very, very stupid indeed and, you know, that I shouldn't go to college, I shouldn't go to university; there were all these things that I just wasn't clever enough to go. And they were probably right, but part of it was because I don't think I've found the thing that I was interested in. And then I went to university to study archaeology, and suddenly I didn't feel so stupid anymore, because archaeology is about every aspect of human life, society, culture, so it's kind of relevant to everything. So through one discipline I was able to study all the things that I'd done badly before but through a different kind of lens that for me was sort of engaging and fascinating. So yes, perhaps I have my poor performance at school and college to thank to sort of taking an interdisciplinary approach, because I still maintain that part. The way that I work is I know very little about lots of stuff, and it's the way I kind of bring them together that turns into something new that people perceive to be slightly more interesting.

As with the other extracts, this one represents an account that is personal and unique but at the same time embedded in wider social debates: who should go to university, what are the downsides of not being considered clever, and what is the path that has to be followed to become a specialist? It is crucial to note that the story Julia provides about herself and the characteristics of her discipline are presented as if they were closely related and highly compatible. To her, it was the interdisciplinary nature of archaeology and the fact that this discipline is 'about everything' that made her interested in it, and once she found this discipline, she 'didn't feel so stupid anymore'. Through her biographical account, she thus portrays herself as being naturally predisposed to work in an interdisciplinary field such as archaeology, just as Lawrence suggested he was somehow predisposed to become a mathematician.

For two of the previous interviewees, Lawrence and Lindsay, describing themselves as academically oriented and skilful since an early age was essential in their explanations of the professional path that they chose to take. By contrast, Julia's account is substantially distant from such a narrative. Rather than prematurely skilful and academically oriented, she was called stupid; instead of passionate about a single discipline since an early age, she found her interests only later on in life; and, instead of presenting herself as a specialist in a specific area, she argues that she now knows 
'very little about lots of stuff'. It might be that in a discipline as broad as archaeology this is a desirable personal characteristic rather than one to avoid. Curiously, while other interviewees intended to repair their breaches from the canonical narrative by playing down the extent of such breaches, Julia instead embraced the interdisciplinarity of archaeology to repair the troubled identity of being perceived as stupid. In that way, while to other interviewees being interdisciplinary was a personal feature to keep low and discrete, to Julia this was a personal feature to emphasise. This might suggest that the way interdisciplinary self-narratives are articulated depends on particular disciplinary contexts and also on the particular interactional and institutional contexts in which they are articulated. For example, in her current university webpage, Julia mentions her interdisciplinary engagement but not her 'stupid' past.

\subsection{Discussion and Conclusion: Narrating Identities and Reproducing Disciplines}

Drawing on Taylor and Littleton's approach and examining the biographical narratives of four scholars involved in interdisciplinary research, this chapter has contributed to the study of the construction of academic, disciplinary, and interdisciplinary identities. This final section summarises the findings of the analysis and discusses them against the backdrop of other existing studies.

The analysis illustrated that despite their involvement in interdisciplinary research, the interviewees provided narrative accounts that pointed to an 'expected' trajectory, namely to one that allowed them to identify themselves as members of specific disciplinary communities. To clarify, the features of this 'expected' trajectory include: (1) descriptions of early interests, passion, and skills in a specific discipline; (2) descriptions of early ambition and a clear career goal; and (3) training and experience within the same discipline from undergraduate degree to $\mathrm{PhD}$, and even beyond. This expected life trajectory can be called the canonical narrative of the single discipline specialist. Consistent with Taylor and Littleton, when the interviewees' accounts deviated from or breached this canonical narrative-for example, because of their engagement with other disciplines-they provided some sort of justification, which could be interpreted as 'repair'.

The features of this narrative, including breaches and the subsequent repair, were more visible in the cases of Blanc, the computer scientist, and of Lindsay, the economist. Blanc argued that even though his work has involved chemists and biologists, this still counts as 'core computer science'; and Lindsay described her engagement with other disciplines 'as a consequence' of her research within economics. A contrasting case was that of Julia, the archaeologist, whose described life trajectory was at a significant distance from the canonical narrative described above. Curiously, and perhaps paradoxically, she drew on her deviation from the expected trajectory to justify her interests and her success in a discipline that is characterised, as Kristiansen (2009) argues, by its interdisciplinary nature and its possibility to 
make connections across disciplines in the arts, the humanities, and the social and the natural sciences.

The latter point reveals one of the most intriguing findings of the analysis, which is that the interviewees described themselves in ways that resembled their main disciplines. Julia's celebration of her broad interests mirrors the breadth of archaeology; by contrast, Lindsay's careful way of describing her engagement with interdisciplinarity resonates with the scientific purity and the insularity that Fourcade et al. (2015) attribute to the discipline of economics. Furthermore, Lawrence's described trajectory is similar to the way in which mathematicians are presented in popular culture. Yet, these 'disciplined' forms of describing themselves are also connected to details of the speakers' lives, such as Julia's and Lawrence's vivid descriptions of their childhood.

Based on these findings, a bold argument can be made. As more than one author has observed (Forman 2012; Schaffer 2013; Sugimoto and Weingart 2015), disciplines seem to be real, homogeneous, and different from each other because of the stories told about them. In a similar way, it would be reasonable to suggest that disciplines are also in part established, maintained, and reproduced through the narratives that individuals tell about themselves. Put differently, as individuals construct their identities, they also construct the identity of their disciplines. This is not an easy task, since individuals have to be able to articulate explanations that make their interdisciplinary engagements look like being part of the 'core' of the discipline and not alien to it. This skill requires an understanding of other wider discourses and narratives that constitute a particular discipline. At times, the chances of success might be low. And yet, the articulation of personal (inter)disciplinary identities may be a way through which the narratives that constitute the 'core' of a discipline become, little by little, more heterogeneous. This suggestion contributes to illustrating Kastenhofer and Monyneux-Hogdson's observation that "communities, their representatives and practitioners... are co-produced" (p. 10).

Pinch (1990) and Brew (2007) have contributed substantially to our understanding of the negotiation of academic identities, emphasising that disciplinary labels are not fixed but flexible. However, the analysis presented here demonstrates that the construction of an academic identity depends on more than the use of disciplinary labels. The successful (i.e. convincing and persuasive) articulation of personal and professional stories through a choreography of expected trajectories, breaches, and innovative repairs might contribute to the acquisition of epistemic power within and beyond an established discipline. In that way, this skill might represent a type of academic or scientific capital as Bourdieu and Garforth and Kerr (2011) understand the term. Garforth and Kerr have suggested that to understand the professional implications of interdisciplinarity, at a time in which disciplinary identity is still relevant (Henkel 2005), studies have to pay attention to specific institutional contexts and to individual academic trajectories. Intending to contribute to this research agenda, this chapter has demonstrated that these individual academic trajectories, as portrayed in biographical narrative, are carefully articulated interactional devices, and, as such, they represent valuable research objects that deserve detailed analytical attention. 


\section{References}

Abbott, A. 2001. Chaos of disciplines. Chicago: University of Chicago Press.

Barry, A., G. Born, and G. Weszkalnys. 2008. Logics of interdisciplinarity. Economy and Society 37 (1): 20-49.

Bartlett, A., J. Lewis, and M.L. Williams. 2016. Generations of interdisciplinarity in bioinformatics. New Genetics and Society 35 (2): 186-209.

Billig, M. 1991. Ideology and opinions: Studies in rhetorical psychology. London: Sage.

2008. The hidden roots of critical psychology. London: Sage.

2012. Undisciplined beginnings, academic success, and discursive psychology. The British Journal of Social Psychology 51 (3): 413-424.

Bourdieu, P. 1988. Homo academicus. London: Polity Press.

Brew, A. 2007. Disciplinary and interdisciplinary affiliations of experienced researchers. Higher Education 56 (4): 423-438.

Bruner, J. 1990. Acts of meaning. Cambridge: Harvard University Press.

Buanes, A., and S. Jentoft. 2009. Building bridges: Institutional perspectives on interdisciplinarity. Futures 41 (7): 446-454.

Calvert, J. (2011). Systems biology, interdisciplinarity and disciplinary identity INNOGEN Working Paper No. 90.

Castán Broto, V., M. Gislason, and M.-H. Ehlers. 2009. Practising interdisciplinarity in the interplay between disciplines: Experiences of established researchers. Environmental Science \& Policy 12 (7): 922-933.

European Commission. 2011. Proposal for a regulation of the European Parliament and of the Council establishing Horizon 2020: The Framework Programme for Research and Innovation (2014-2020).

Felt, U., J. Igelsböck, A. Schikowitz, and T. Völker. 2013. Growing into what? The (un-)disciplined socialization of early stage researchers in transdisciplinary research. Higher Education 65: 511-524.

Fisher, E., and D. Beltran-del-Rio. 2010. Box: Mathematics and root interdisciplinarity. In The Oxford handbook of interdisciplinarity, ed. R. Frodeman, J.T. Klein, and C. Mitcham, 88-91. Oxford: Oxford University Press.

Forman, P. 2012. On the historical forms of knowledge production and curation: Modernity entailed disciplinarity, postmodernity entails antidisciplinarity. Osiris 27: 56-97.

Fourcade, M. 2009. Economies and societies: Discipline and profession in the United States, Great Britain, and France, 1890s to 1990s. Princeton: Princeton University Press.

Fourcade, M., E. Ollion, and Y. Algan. 2015. The superiority of economists. Journal of Economic Perspectives 29 (1): 89-114.

Garforth, L., and A. Kerr. 2011. Interdisciplinarity and the social sciences: Capital, institutions and autonomy. The British Journal of Sociology 62 (4): 657-676.

Gergen, K. 1973. Social psychology as history. Journal of Personality and Social Psychology 26 (2): 309-320.

Gleason, P. 1983. Identifying identity: A semantic history. The Journal of Americal History 69 (4): 910-931.

Gross, N., \& Solon, S. (2007). The social and political views of American professors Working Paper.

Haynes, R.D. 2016. Whatever happened to the 'mad, bad' scientist? Overturning the stereotype. Public Understanding of Science 25 (1): 31-44.

Henkel, M. 2005. Academic identity and autonomy in a changing policy environment. Higher Education 49 (1-2): 155-176.

Holley, K.A. 2015. Doctoral education and the development of an interdisciplinary identity. Innovations in Education and Teaching International 52 (6): 642-652.

Huutoniemi, K., J.T. Klein, H. Bruun, and J. Hukkinen. 2010. Analyzing interdisciplinarity: Typology and indicators. Research Policy 39 (1): 79-88.

Klein, J.T. 1990. Interdisciplinarity. History, theory \& practice. Detroit: Wayne State University Press. 
2010. A taxonomy of interdisciplinarity. In The Oxford handbook of interdisciplinarity, ed. R. Frodeman, J.T. Klein, and C. Mitcham, 15-30. Oxford: Oxford University Press.

Klein, J.T., and H.J. Falk-Krzesinski. 2017. Interdisciplinary and collaborative work: Framing promotion and tenure practices and policies. Research Policy 46 (6): 1055-1061.

Kristiansen, K. 2009. The discipline of archaeology. In The Oxford handbook of archaeology, ed. B. Cunliffe, C. Gosden, and R.A. Joyce, 3-46. Oxford: Oxford University Press.

Leahey, E., C.M. Beckman, and T.L. Stanko. 2017. Prominent but less productive: The impact of interdisciplinarity on scientists' research. Administrative Science Quarterly 62 (1): 105-139.

Mialet, H. 1999. Do angels have bodies? Two stories about subjectivity in science: The cases of William X and Mister H. Social Studies of Science 29 (4): 551-581.

Michael, M. 1996. Constructing identities. The social, the nonhuman and change. London: Sage. National Academy of Sciences. 2005. Facilitating interdisciplinary research. Washington, DC.

OECD. 1972. Interdisciplinarity, problems of teaching and research in universities. Paris: Organisation for Economic Co-operation and Development.

Pfirman, S., and P.J.S. Martin. 2010. Facilitating interdisciplinary scholars. In The Oxford handbook of interdisciplinarity, ed. R. Frodeman, J.T. Klein, and C. Mitcham, 387-403. Oxford: Oxford University Press.

Pinch, T. 1990. The culture of scientists and disciplinary rhetoric. European Journal of Education 25 (3): 295-304.

Potter, J., and M. Wetherell. 1987. Discourse and social psychology. London: Sage.

RCUK. 2015. Institutional website. https://www.epsrc.ac.uk. Accessed 22 June 2018.

Schaffer, S. 2013. How disciplines look. In Interdisciplinarity. Reconfigurations of the social and natural sciences, ed. A. Barry and G. Born, 57-81. Abingdon: Routledge.

Sugimoto, C.R., and S. Weingart. 2015. The kaleidoscope of disciplinarity. Journal of Documentation 71 (4): 775-794.

Taylor, S. 2007. Narrative as construction and discursive resource. In Narrative-State of the Art, ed. M. Bamberg, 113-122. Amsterdam: John Benjamins Publishing Company.

Taylor, S., and K. Littleton. 2006. Biographies in talk: A narrative-discursive research approach. Qualitative Sociology Review 2 (1): 22-38.

- 2008. Art work or money: Conflicts in the construction of a creative identity. The Sociological Review 56 (2): 275-292.

. 2012. Contemporary identities of creativity and creative work. Surrey: Ashgate.

Turner, S. 2000. What are disciplines? And how is interdisciplinarity different? In Practising interdisciplinarity, ed. P. Weingart and N. Stehr, 46-65. Toronto: University of Toronto Press.

Wetherell, M. 2008. Subjectivity or psycho-discursive practices? Investigating complex intersectional identities. Subjectivity 22 (1): 73-81.

. 2010. The field of identity studies. In The SAGE handbook of identities, ed. M. Wetherell and C.T. Mohalty, 3-26. London: Sage.

Open Access This chapter is licensed under the terms of the Creative Commons Attribution 4.0 International License (http://creativecommons.org/licenses/by/4.0/), which permits use, sharing, adaptation, distribution and reproduction in any medium or format, as long as you give appropriate credit to the original author(s) and the source, provide a link to the Creative Commons license and indicate if changes were made.

The images or other third party material in this chapter are included in the chapter's Creative Commons license, unless indicated otherwise in a credit line to the material. If material is not included in the chapter's Creative Commons license and your intended use is not permitted by statutory regulation or exceeds the permitted use, you will need to obtain permission directly from the copyright holder.

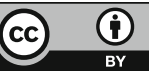

